\title{
Impact of Industry 4.0 on Aerospace and Defense Systems
}

\author{
Nedim Tabaković ${ }^{1}$, Benjamin Durakovic $\mathbf{c}^{2^{*}}$ \\ ${ }^{1}$ Software Engineering, International University of Sarajevo, Bosnia and Herzegovina \\ ${ }^{2}$ Industrial Engineering, International University of Sarajevo, Bosnia and Herzegovina
}

*Corresponding author: bdurakovic@ius.edu.ba

(C) The Author

2021.

Published by

ARDA.

\begin{abstract}
The aim of this article is to address key features and the wave of new technologies that Industry 4.0 brings to Aerospace and Defense Systems. This research paper enthusiastically depicts what the future of the Aerospace and Defense industry could be while also providing information about those braves enough to already step into the world of all around digitalization. With this approach, the aim is to interconnect every step of the operation towards creating a mostly perfect environment which cuts off any human mistake and guarantees increase in revenue stream and customer satisfaction.

The main method of implementation of Industry 4.0 to many industries is digitalization. Digitalization is the digital upgrade to any company or industry which, when applied correctly, guarantees nothing but success in revenue streams and customer service. This process is a complex blend of many modern technologies and implementing such a hefty upgrade might be problematic to those who have been surviving on very old business models for tens of years.

Industry 4.0 is a fast-changing environment and those who are quickly adapting to this wave of change are setting themselves for success. The primary goal of this research paper is to provide an insight into the world of technology Industry 4.0 offers and how that technology could help Aerospace and Defense create a portal to the future.
\end{abstract}

Keywords: Industry 4.0, Technology, Aerospace and Defense Systems, IOT

\section{Introduction}

Industry 4.0, otherwise called as the Fourth Industrial Revolution represents a step into the future of human kind. With built-in sensing systems in nearly all industrial materials, goods, and facilities, Industry 4.0 allows the manufacturing field to become digitalized [1].

From product development and buying through production, shipping, and service, Industry 4.0 digitizes and integrates activities vertically throughout the whole organization. All data on operations processes, process efficiency and quality control, as well as operations planning, is available in real time, supplemented by augmented reality, and optimized in a network [2].

The fourth technological revolution is now underway in human society. It's said to be the next big thing, revolutionizing human relationships, thinking, and, most importantly, working [3]. Industry 4.0 is a manufacturing system that combines operational technology (OT) with information technology (IT) [4]. But fortunately, countries do meet those requirements, and many are still, slowly, but surely going towards that goal of digitalization.

This work is licensed under a Creative Commons Attribution License (https://creativecommons.org/licenses/by/4.0/) that allows others to share and adapt the material for any purpose (even commercially), in any medium with an acknowledgement of the work's authorship and initial publication in this journal. 


\section{Industry 4.0 Market}

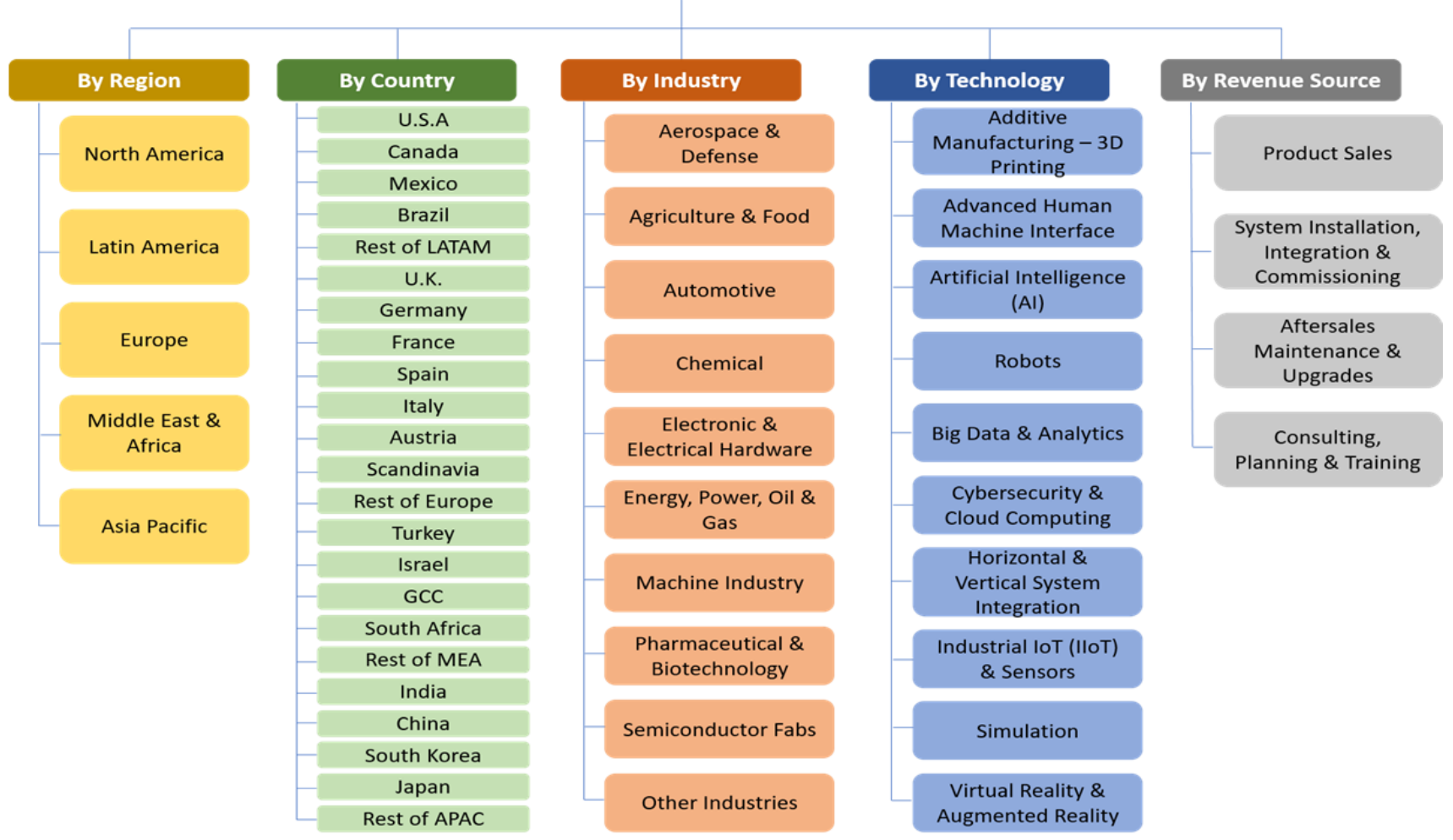

Figure 1. Industry 4.0 market - the overall implementation and usage

Industry 4.0 is divided into three categories. Horizontal integration is the first. It introduces the idea of a new kind of global supply chain network. Vertical integration is the second. The idea is to create hierarchical subsystems on the production line in order to create a line that is simple to configure and flexible. The final aspect is engineering convergence across the entire supply chain, from beginning to end, to aid in product customization [5].

Industry 4.0, as on many other things, has a great impact on defense systems. Industry 4.0 is based on the digital transformation of processes and in the means of defense systems - the complete automation of drones and other defense systems. As a result of Industry 4.0, the whole business is already seeing benefits from taking human error out of the equation. Artificial intelligence and such technological advancements might pose an improvement in other fields, but as for aerospace and defense systems it poses some ethical questions which come in play when we think about all of the possibilities of automated technologies in defense systems. As we know, the whole world is leaning towards digitalization of every aspect of our lives. Although some can precipitate this as an attempt to "upload" the whole planet to computers and a way for some higher power to control our everyday lives, Industry 4.0 actually represents an attempt at somewhat perfecting every possible process (with sensors and internet connectivity). For customers who depend on those processes, Industry 4.0 represents the perfecting of their customer service. Industries overall are experiencing an increase in customer complaints, quality standard pressure, time precision, etc. So, we can just imagine what an impact Industry 4.0 has had on Aerospace and Defense systems which already are almost perfect in every way.

Applying such a broad change to the whole industry is not an easy task and as such couldn't be done in a few simple steps. Instead, Industry 4.0 is implemented through the entire makeover of a company network. However, all of those steps can be organized into reworking connectivity, customizability and intelligence.

Reworking connectivity means the entire communication structure previously defined. Being well organized and in touch, a company really becomes a living breathing creature. The ecosystem of one company blooms, rewarding its budget and schedule. But, being in Industry 4.0, companies are all interconnected, which helps take off the industry to a whole another level. Such changes are done by introducing digital threads. A digital thread is the communication framework which guarantees connected data flow, smarter integrated structure and smarter ecosystem [6]. As previously said, such changes are done by implementing many core changes to how the system already operates which means integrating a software platform which is used by the whole of the operation. 
Pros of including such a system are:

- interconnectivity of the company and supply chain,

- better customer and customer complaint and request management,

- manufacturing and workforce efficiency increase,

- reworking customizability.

This digital thread approach has already shown some results in the form of efficiency growth at about $16 \%$ [7]. The digitalization of one company or company supply chain is not an easy task but brings a lot of room for financial growth and better overall connectivity. Digitalization consists of many things such as: Internet of Things - IoT, augmented reality and virtual reality, large data processing, cloud computing, cyber security changes and much more. This just goes to show on that implementing such a system is not an easy task and consists of a lot of steps. However, companies which catch on early on this train of industrial revolution are already setting themselves up for success, as the results show.

An overall name for this change is "digitalization" and apart from the already mentioned features, it brings many more features which will be mentioned later on in the text.

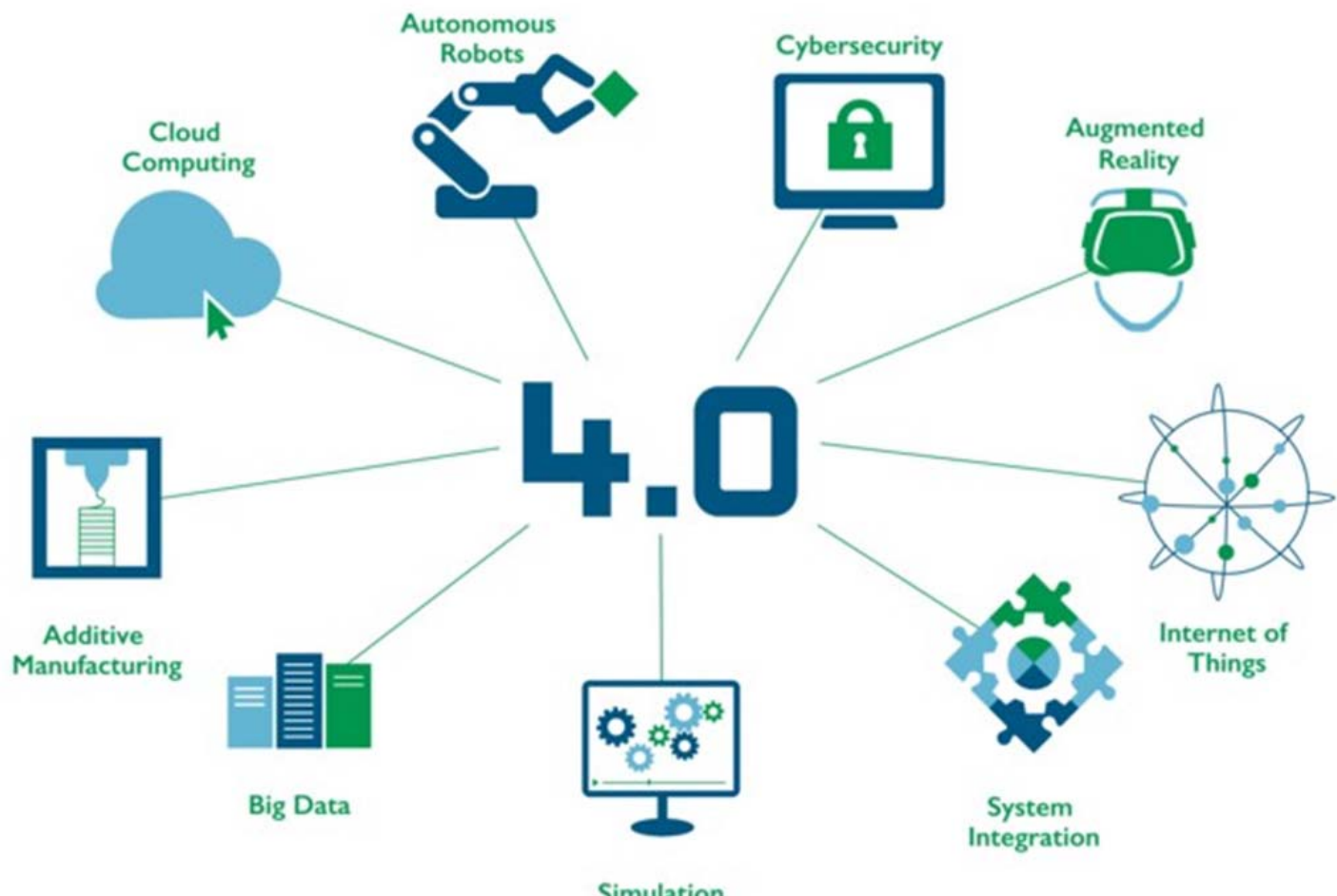

Figure 2. A visual representation of all of the improvements and features Industry 4.0 brought [6]

In theory, all of the features Industry 4.0 brings should help every Aerospace and Defense company reach higher success and acquire remarkable financial goals, however, in reality things are a lot different. Despite all of the excitement Industry 4.0 brings to all industries, the reality is different. Due to many reasons like digital illiteracy and lack of financial support, companies are forced to abandon the idea completely or settle for less rewarding results and minor changes. About 3\% of all digital transformation initiatives within the Aerospace and Defense industry were succesful, $29 \%$ initiatives failed completely and $69 \%$ of initiatives settled for "suboptimal" results [8]. Unfortunately, the technology might be too advanced to grasp in this exact moment but we believe it is progressing by day. Of course, setbacks like lack of financial support cannot be avoided, but company owners getting educated on the issue of digitalization is mandatory. A chance like such is not something to be ignored and companies that succeed in their intention of digitalizing their bussiness model are probably going to be greatly rewarded in the near and far future.

In the next section we will discuss some issues and challenges which make the process of digitalization a struggle for many companies. 


\section{Challenges and issues}

\subsection{Digital illiteracy of company owners}

As a lot of companies are owned by corporation which is digitally illiterate, most attempts of implementing new technologies at such companies result in failure. Indeed, 70 percent of corporate digital transformation programs fail due to a lack of digital literacy or awareness. A notable illustration of this appears to be the leadership of A\&D defense corporations [7].

This could present a great problem for those companies as Industry 4.0 is a fast moving change and taking early position in it could result in greater outcome. Adapting late to change could cost those companies a lot of money or even the survival of the company. So, for a company to survive today's climate, it needs to be digitally literate [8].

\subsection{Lack of financial support from corporation}

Of course, this is tied closely to the digital illiteracy part. Digitally illiterate corporation might not realise how important it is to accept changes and to invest in Industry 4.0. Time is a very important factor in Industry 4.0, as mentioned before, and by missing the chance to incorporate it into the whole system and defying the boundaries could cost these companies a lot of money.

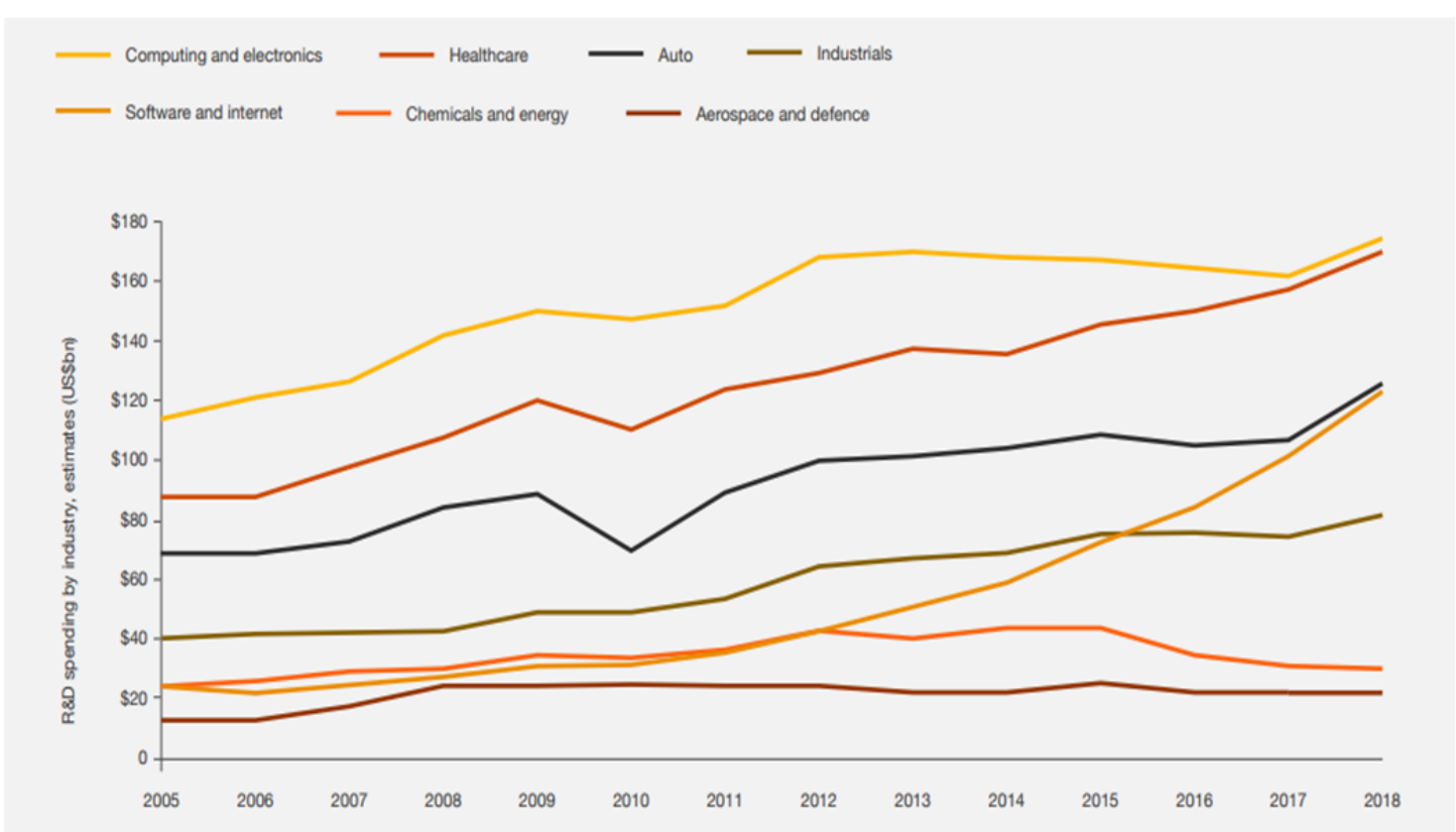

Figure 3. Overall interest in the Aerospace and Defense (marked maroon red) by US investors from 2005 to $2018[9]$

Overall investment in Aerospace and Defense R\&D by US investors from 2005 to 2018 is presented in Figure 3. In the US most of the Research \& Development investment were made by business [60], as shown in Fig. 3.

Air travel is becoming more popular, thanks to a rising middle class in emerging nations, millennial aspirations, and lower prices. The use of digital technology to match customer expectations will be critical to seizing this opportunity. These expectations have been formed in part by experiences in other industries, such as retail and entertainment, and today include more streamlined and integrated purchase trips, seamless travel, and customized, on-demand services [10].

Now, for a company to be successful in this wave of Industry 4.0, they need to be ready to complete some prerequisites. To be able to keep up with the new age of technology and industry evolving, companies need to be ready to accept changes and to easy conform to any changes. 


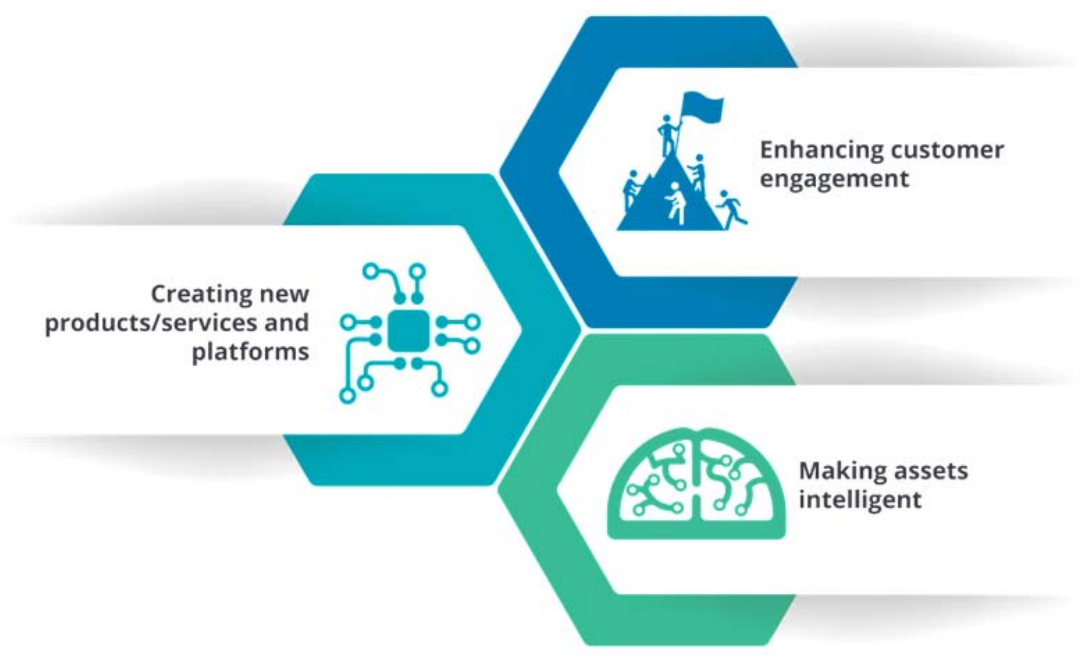

Figure 4. Three levels of digital Transformation at Aerospace and defense enterprises [54]

Figure 4. shows a digital transformation (digitalization) visualized by Deloitte Insights in three levels which companies must surpass to digitalize their business and work organization. These are three more goals of what the digital thread is trying to achieve: new services, enhancing customer engagement and making assets intelligent and interconnected [54].

\section{Changes}

Company giants which had a steady up rise during a long period of their existence and are used to a more traditional approach are being shaken up by newcomers who rely on the new industry strategies. This is why, by the standards of industry 4.0, change is better for those who are ready to accept it. Between those changes, we need to give importance to following.

\subsection{Being agile}

Between Industry 4.0's main improvements, one worth mentioning is being precise and agile, especially in the manufacturing sector. In Aerospace and Defense, such is accomplished by taking the traditional approach of manufacturing (physical and system testing) and amping it up to meet the customer needs. For example, in September 2018, the number of aircrafts reached the highest peak in 9 years. To be prepared for such speed of manufacturing and delivering, companies are starting to implement newer techniques towards keeping up with the newfound competition. The company under the name of Airbus joined a research program founded by the EU, called Ramp-Up.

This program is built for aircraft companies to research new technologies and develop better strategies to be able to fulfill all customer demand. Airbus initially tested the manufacturing process according to the RampUp program and found that the cost of the new materials and techniques actually cut off in half in contrast of their previous manufacturing cost [11].

\subsection{Redesign of current business models}

Since Industry 4.0 heavily relies on the use of new technologies, sensors and data measuring devices being a part of them, using the collected data may be the only way to advance in today's age. By recording customer feedback as well as any other possible technical and or financial information, by molding their new business model by these new parameters, the company is set for success as they provide only what makes them grow. For example, the aircraft manufacturing company Boeing recently developed their data collecting program called "AnalytX" which is consisted of customers exploring and traveling their data-based travel plans that deliver information about fuel efficiency and notable operational setbacks. [12] 


\subsection{Supply chain improvements}

By collaborating closely with vendors, Aerospace and Defense manufacturers are maintaining innovation and mutual collaboration towards the goal of sharing the best strategies and practices for fulfilling the new challenges of the supply chain. The manufacturers accomplish this by using digital design, integration and simulation. This way, they don't need to spend unnecessary time on prototypes. By supplying this information to the supply chain, the supply chain becomes transparent and visible which speeds up the whole process. In other words, all companies, being it manufacturing or part supply vendors, need to work together towards a great goal. BoostAeroSpace, a supply chain between the European Aerospace and Defense manufacturers is an example of this. They provide any information needed between all suppliers, them being underdogs or well-known manufacturers [13].

The art and science of managing physical, financial, and information flows from the production of raw materials to end customers is known as supply chain management. Two current trends pose a threat:

1. changes in information technology are permitting better coordination and analytical evaluations as a result of globalization;

2. globalization necessitates managing increasingly complicated and geographically distributed flows [14].

\subsection{Cyber-security challenge}

With all of this, being private earlier, now being shared between companies via clouds and the internet, they face the new risk of their cyber-security being scrutinized. Cyber-security issues present a great threat and a setback in these companies progress towards being by all means Industry 4.0. So, protecting or intellectual property and ensuring the safety of the data being shared, companies needed to form cyber-security operational centers (CSOC). The main goal of these centers is to detect threats, collect intelligence, respond to incidents, form a team of digital forensics, and monitoring and possibly avoiding cyberattacks [15].

The current problem for the A\&D industry is two-stepped. First, the industry must endeavor to stay two steps ahead of the cyber danger rather than simply one. They need to keep investing in new capabilities, technologies, and concepts. They must remain attentive in the face of a danger that is exceedingly adaptable. They also need to put a greater emphasis on building security into their goods from the start. At the same time, A\&D players will need to guarantee that any weaknesses in their present cybersecurity posture are filled [16].

\subsection{Industry 4.0 inspired system}

Aerospace \& Defense 4.0 is the application of Industry 4.0 technologies in the A\&D industry for developing new cost-effective products and services, making existing products smarter using sensors and connectivity, and leveraging advanced manufacturing processes such as additive manufacturing, among other [17]. Creating a sustainable, inner-connected system based on Cloud technologies, Big Data, Internet of Things (IOT) etc. is also referenced as creating a "Digital Thread". A Digital Thread is a system which is consisted of every possible work aspect of one company which are connected and relying on each other.

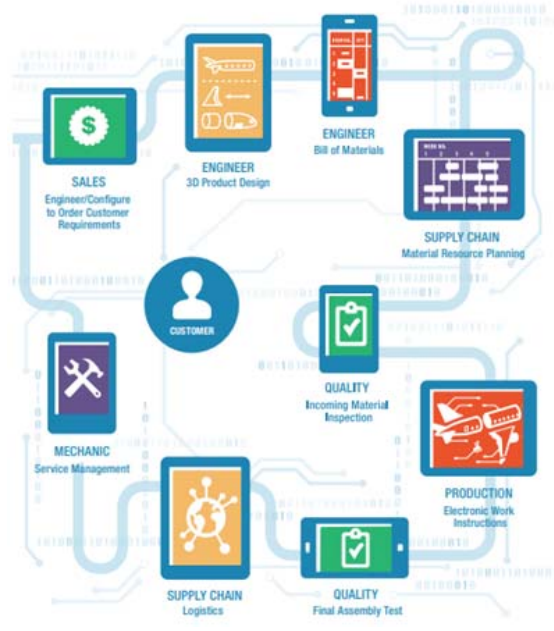

Figure 5. Loop diagram of a never-ending cycle of one's product manufacturing [18] 
Each section is interconnected and does its own part towards serving the customer. Every branch is interconnected and works like a living breathing creature. The flow of information in these kinds of structures is the most important factor, and the digital thread is a perfect, never-ending loop of information [18].

\section{Features and improvements of Industry 4.0}

\subsection{Being efficient}

Productivity growth is at the heart of every industrial revolution. Previous industrial revolutions had a significant impact on the manufacturing process itself. Companies increased their production by using the steam engine, electricity, and the transition from analogue to digital technology, for example. The fourth industrial revolution, on the other hand, has a broader impact, affecting not only production but other indirect departments, particularly engineering processes. That indicates that improving brainwork and decisionmaking processes has the greatest potential for increasing productivity. This process can be accelerated with collaboration at all levels [19].

For A\&D, digitalization means the improvement of already well-established systems. Companies which choose to implement Industry 4.0 in their processes, benefit from not having to manually and physically test their products. They can instead test their products with simulation software which cuts costs and guarantees time efficiency. For example, the company "Airbus" which is a manufacturer of aircrafts, decided to conduct simulations for the assembly of their "A350" aircraft to ensure that the new design and new more advanced materials do not result in unnecessary cost. The result has shown that the cost of the whole development was cut in half compared to competitor companies [20].

\subsection{New business models}

Companies can use all of the sensor and system information gathered towards creating new business models which are more efficient, cost less and create better customer service. It would take a lot of time to create a business model from the data gathered, but using software, the issue is solved in minutes and business models are created overnight. In terms of $A \& D$, companies might use data collected to create more efficient Fuel economy, organize flight plans which suit more customers etc.

New enabling technologies like Big Data, Cloud Computing, Collaborative Robots, Additive Manufacturing, Artificial Vision, or Augmented Reality are being introduced solely to improve the value creation architecture (key resources and activities) by increasing efficiency and improving performance (reducing costs, time, and failures, employee training, and so on). This might be the first step toward traditional industrial enterprises adopting Industry 4.0 without taking on significant risks [21].

\subsection{Supply chain and logistics changes}

Companies can achieve optimal productivity and cost savings by establishing supply chains that are much more effective and do not depend on humans using high-performance quantum computing. This means that this technology can reduce errors (particularly human errors) and improve logistics and inventory management. This type of technology will take the form of a portal that manufacturers and vendors can use. A network called "AirDesign," which is a platform for collaborative creativity in the A\&D industry, is an example of this technology [22].

\subsection{Cyber security improvement}

Until recently, cybersecurity was primarily concerned with defending organizational perimeters, that is, preventing illegal access to a privately owned computer network. To protect the perimeter from hackers, the most common technique was to install safeguards such as firewalls, intrusion detection systems, and virus protections at the perimeter's entrance. As Industry 4.0 blurs the lines between the real and digital worlds, this cybersecurity approach is quickly becoming obsolete. Similarly, communication technology, in combination with social and cultural considerations, are altering working patterns in the direction of "anywhere, anytime" [23].

For A\&D companies, security and cybersecurity is something very important. With the introduction of Industry 4.0 and digitalization, companies are more exposed to risk as the data they now digitally store could potentially be harmed. This calls for the betterment of their security systems which automatically improves 
the overall security of one company. In other words, because digitalization poses a possible challenge and an issue with cybersecurity, companies spend more time designing a better cybersecurity system which protects everything.

As the need of creating strong levels of digital trust grows, so does the relevance of transparency and nonrepudiation, which provide verification of the integrity and origin of one's own and third-party data. Strong risk management and data integrity solutions can help businesses avoid breaches and effectively manage operational disruption [24].

\section{Industry 4.0 methods}

Many Industry 4.0 technologies could support the aerospace and defense industries. However, while not every invention or method would be useful in the long term, they all have the same function of interacting with one another to form a "world ecosystem" [25]. As it was mentioned earlier, digitalization is consisted of many features which work together towards a better goal. Methods of Industry 4.0 that can be used for Aerospace and Defense systems following.

\subsection{Internet of things}

There are over 20 IoT characteristics that can complement and add benefit to aerospace systems in a variety of ways, including reducing consumer pain points including flight termination and delays, but the most important ones are:

- Interconnectivity - Interconnection is maintained when all of the sensors and systems are interconnected via internet [26].

- Things-related services - Within the limits of things, such as privacy protection and semantic coherence between real and virtual things, the IoT can provide thing-related services. Both the physical and information world technologies will have to alter in order to deliver thing-related services within the restrictions of things [27].

- Heterogenity - The IoT devices are heterogeneous, since they are based on many hardware platforms and networks. Through various networks, they may communicate with other devices or service platforms [28].

- Dynamic changes - Device states, such as sleeping and waking up, being connected and/or disconnected, and the context of devices, such as location and speed, alter dynamically. Furthermore, the number of devices might fluctuate.

- Enormous scale - The number of devices that will need to be controlled and interact with one another will be at least an order of magnitude greater than the existing Internet's gadgets [29].

- Safety - The obligation to preserve the legitimate interests of users and the integrity of the ecosystem that links them is implicit in the freedom to innovate. This is especially true when the Internet expands into physical areas and the availability of next-generation technologies and artificial intelligence grows [30].

- Connectivity - Connectivity is self-explanatory. Through industry 4.0, everything and anything is interconnected and that greatly helps towards building a massive, breathing and living system which can ease the process of manufacturing and getting information by a great margin $[32,33]$.

\subsection{Big data analytics}

Big Data is a modern wave of technology and architectures that are developed to derive value from massive data volumes with a wide range of data types, enabling real-time computation and analysis. The "digital plane" of today, which can capture up to 300,000 parameters based on the length of the flight and the type of aircraft, is a direct example of Big Data's effect on the aerospace industry. According to one big aircraft maker, data sharing will grow by $14 \%$ in the next few years [34].

The phrase "Big Data" refers to the development and application of technologies that offer the appropriate user with the right information at the right time from a massive amount of data that has been expanding 
exponentially in our society for a long time. The issue is not just dealing with fast expanding data volumes, but also handling more varied forms as well as increasingly complicated and interlinked data [35].

Simulation - as expected, simulation is up there with the most important innovations and techniques of Industry 4.0. Simulation may be used to test product designs, systems, and device configurations. Simulating risky flight conditions, like all other facets of aviation, can be done by simulation. Simulators are particularly well suited to training scenarios that are inefficient, impossible, risky, or costly to replicate in a live setting. Many potentially risky conditions can only be encountered infrequently by aircrew. If these circumstances arise, they must be dealt with quickly in order to prevent drastic repercussions. Simulators may be used to expose trainees to certain unique conditions in a repeatable and controlled way, with little danger to the pilot, aircraft, other operators, or the environment [36]. Simulation has become a significant technique for supporting and developing a wide range of systems in the twenty-first century. Simulation has enormous promise for the creation and enhancement of products and industrial processes. Simulation is a potent and well-known methodology for addressing the manufacturing industry's present difficulties. Industrialized nations frequently struggle to maintain the expanding industrial sector within their borders. New manufacturing plants are being created from the ground up to conform to the trend of mass customization over mass production while enhancing profitability [37].

\subsection{Augmented reality}

In the aerospace and defense industries, augmented reality will aid engineers in the development of new technologies as well as the improvement of existing systems by including 3D graphics of drawings and simulations for whatever is being designed. The aim of this category is to make guidance easier to interpret if they were available as 3D models superimposed on the real equipment demonstrating how the activities are to be performed step-by-step with illustrations to make the directives ever more clear [38].

Overall, the usage of Augmented Reality in the industry domain is very important because it greatly improves communication in product design and production development: it aids in the early detection and avoidance of design errors; it reduces the number of physical prototypes and saves time and money for businesses. In many industrial applications, augmented reality is seen as a beneficial tool for enhancing and speeding up product and process development [39].

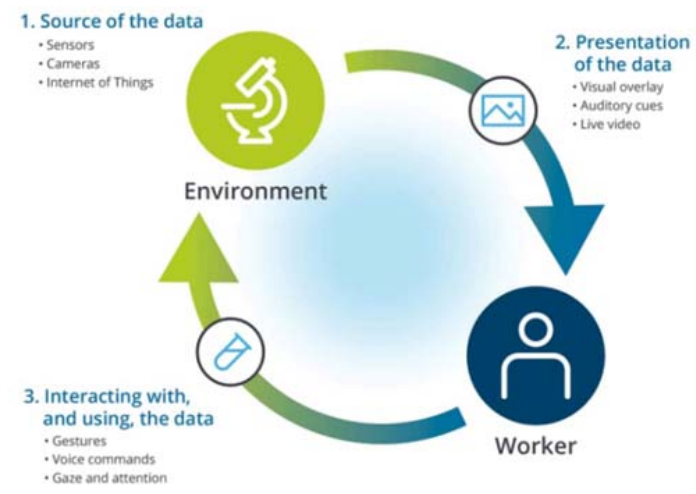

Figure 7. Augmented reality organization [40]

Figure 7. is a visual representation of an augmented reality work organization between workers, the data (sensors, cameras, Internet of Things IoT), the presentation of the data (overlays, audio cues and live representation) and the interaction with the data (gestures, voice commands, gaze and attention). This all results in an environment which takes use of Augmented Reality [40].

\subsection{Advanced analytics (for monitoring real-time aircraft health and identifying system failures in advance)}

The continual rise of the aviation sector has produced a highly competitive environment in which airline businesses are trying to stay afloat in a market with poor profit margins. Consistently more rigorous maintenance schemes have resulted in an increase in aviation safety, despite increasing expenses. To stay competitive, airlines are decreasing total cost by running their operations as smoothly as possible. As a 
consequence of technological improvements in the business, the availability of flight data has risen, causing airlines to monitor their fleet's behavior more thoroughly. The aircraft's systems gather flight data, which is then decoded and transmitted to the engineering, maintenance, and safety departments for interpretation and analysis [41].

\subsection{Digital reality (replacing assembly manuals with smart-glasses)}

Body-tracking and motion-tracking capabilities are core features, allowing a user to manipulate and move objects using haptic controllers, head-mounted displays, and headsets [42]. Such technologies can be used for manipulating assembly manuals and instructing assembly workers on creating aero systems and machines as well as for many other uses.

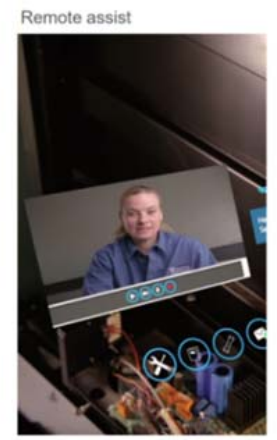

(20) thyssenkrupp

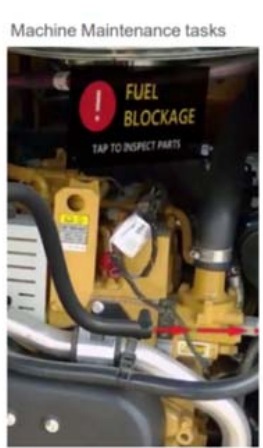

cAT

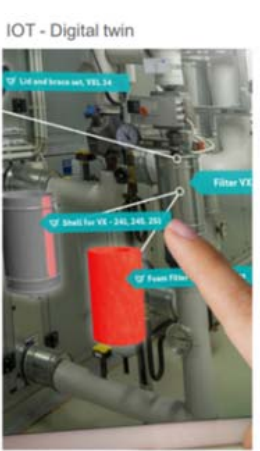

IBM

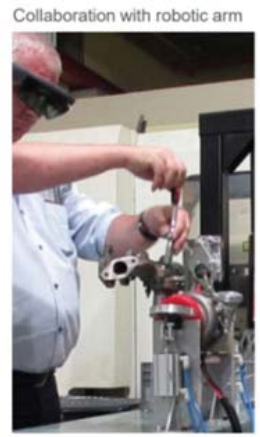

OPEL $\odot$

Figure 8. Integration of digital reality in assemblies / manufacturing processes [43]

Figure 8. shows different ways of digital reality integration into assemblies and manufacturing processes by worldwide companies. It can clearly be seen what can be accomplished with use of some kind of headwear which projects information associated with a part in the machine [43].

Computers, processing power, the internet, cloud computing, and the Internet of Things are all part of the fourth industrial revolution. Virtual Reality is used in Industry 4.0 to reduce design and manufacturing costs, maintain product quality, and solve technological tradeoffs such as decreasing rendering complexity while maintaining high refresh rates or improving resolution while maintaining a stable VR experience. Virtual Reality is an undeniably unique tool with numerous applications, ranging from teaching students all over the world to simulating safety scenarios. However, it must be integrated with viable use case scenarios and realtime data collection in order to capture physical movement and provide a pleasant VR experience [44].

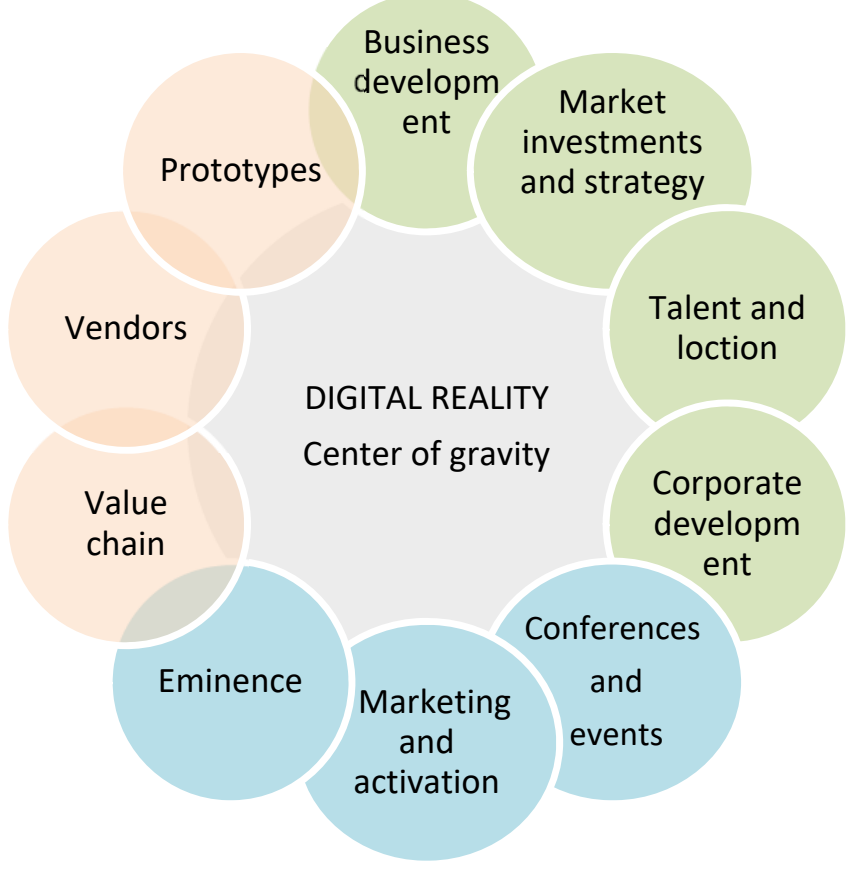

Figure 9. Digital reality [45] 
Figure 9. shows al of the opportunities Digital Reality creates as the center of its own solar system. Many scientists and scholars agree that a system like it can create many opportunities for a lot of people of the world. It is the center of gravity for many industry branches, events, investments, ideas and eminence [45].

\subsection{Autonomous robots}

Autonomous robots are robotic systems which demand no human interaction or effort other than building them and can be used for many actions in aerospace and defense, basically any physical action a human can do, a robot can replicate. Currently, many companies that use autonomous robots have implemented them for targeted functions within their supply chain, piloting various robots to verify expected efficiency gains. As innovative companies grow and expand operations, robots that build robots could be the norm for economically and efficiently optimizing manufacturing operations [46].

Intelligent automation has a history in the A\&D sector, including so-called "smart" weaponry developed by top-tier military and space missions powered by modern technology. The creation of new and interesting methods to add value to domestic and global A\&D supply chains will continue to be driven by that inventive attitude [47].

\subsection{Cloud computing}

Cloud computing is a system that provides usable information within a certain company, workspace or organization. Cloud computing offers flexible access to computing resources, providing both efficiencies and challenges to the aerospace industry where proprietary information not only is business critical but also can be a national security risk if exposed inappropriately [48].

Nitha Rachel shows how cloud computing is utilized to host services on a ground station, which subsequently gives services to airplanes passing through the area. A VM (Virtual Machine) will be relocated from one node to another node on a different cloud in a new geographical region when an aircraft transfers from one geographical network to another. It also defines an aviation data network with a virtual private cloud that uses an IPSec connection to deliver cloud services [49].

\subsection{Additive manufacturing}

Additive manufacturing is a process of printing certain parts of a mechanical system, otherwise known as 3D printing. Additive manufacturing (AM), is a manufacturing technique that builds objects layer by layer using materials such as polymers, metals, and composites.

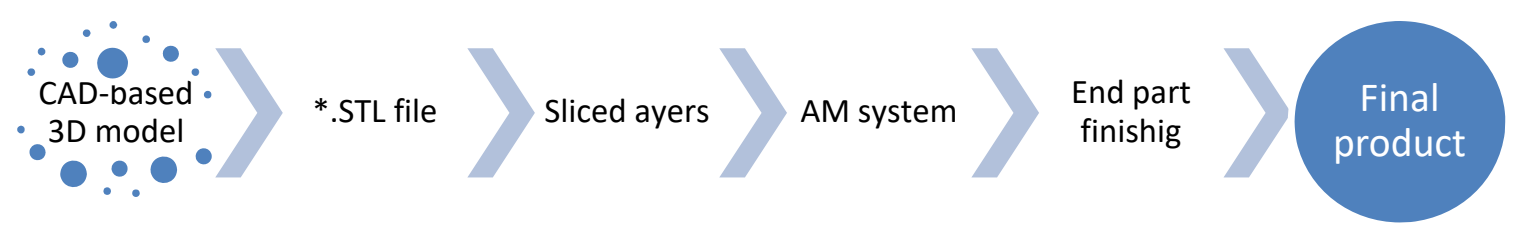

Figure 10. Additive manufacturing process

Figure 10. shows a visual representation of the process of additive manufacturing, also known as 3D printing in which the manufacturing of a turbine goes through 5 steps towards its completion. It firstly is designed in CAD software, then it is processed to a .STL file, the layers are sliced and sent into the AM system in which it is printed and lastly assembled [50].

\subsection{Industrial Internet of Things}

Industrial Internet of Things is a technology dealing with the interconnection of physical devices along with inter-relation of data via internet without requirement of human to machine or human to human interaction. As Internet of Things (IOT) it can be used for manufacturing aero systems and by doing it this way, errors and especially human errors could be avoided efficiently.

By connecting devices and data, IoT presents opportunities for organizations to transform themselves, gain entry into new markets, and harness data to drive more timely and powerful business decisions [51]. 
Applications in the following sectors may have the greatest immediate effect from Industrial IoT from these features:

- bringing together information from suppliers, logistics providers, and customers;

- data from new technologies, peripherals, tools, and equipment are introduced;

- production in a distributed environment requires adding of additional data sources, locations, and owners;

- raw materials, parts, goods, and orders going through organizations are all equipped with sensors [52].

\section{Quantitative diagrams of industry 4.0's usage}

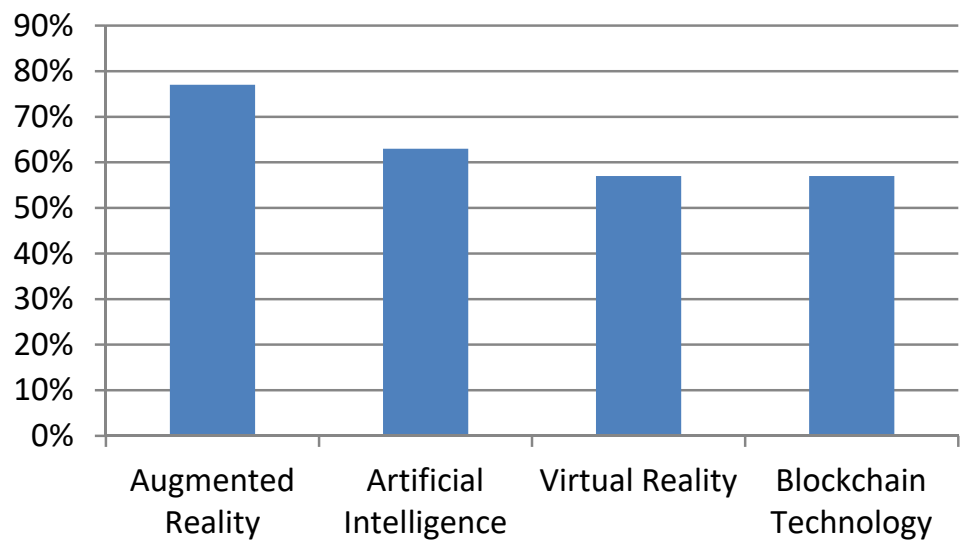

Figure 11. Usage of Industry 4.0 technologies and features by Aerospace and Defense companies in 2017

Figure 11. shows a quantitative value of the usage of Industry 4.0 technologies, features and services by all of Aerospace and Defense companies in 2017. It encompasses following:

- $77 \%$ - augmented Reality - used for sales and marketing (interaction with customers),

- $63 \%$ - artificial Intelligence - used for collecting product sales and customer usage data,

- $57 \%$ - virtual Reality - used for design techniques, walk-ins and tutorials,

- $57 \%$ - blockchain Technology - used for managing configuration data [53] .

Due to many aviation companies implementing digitalization into the core of their systems in Industry 4.0, we can see the "boom" Industry 4.0 made in 2015.

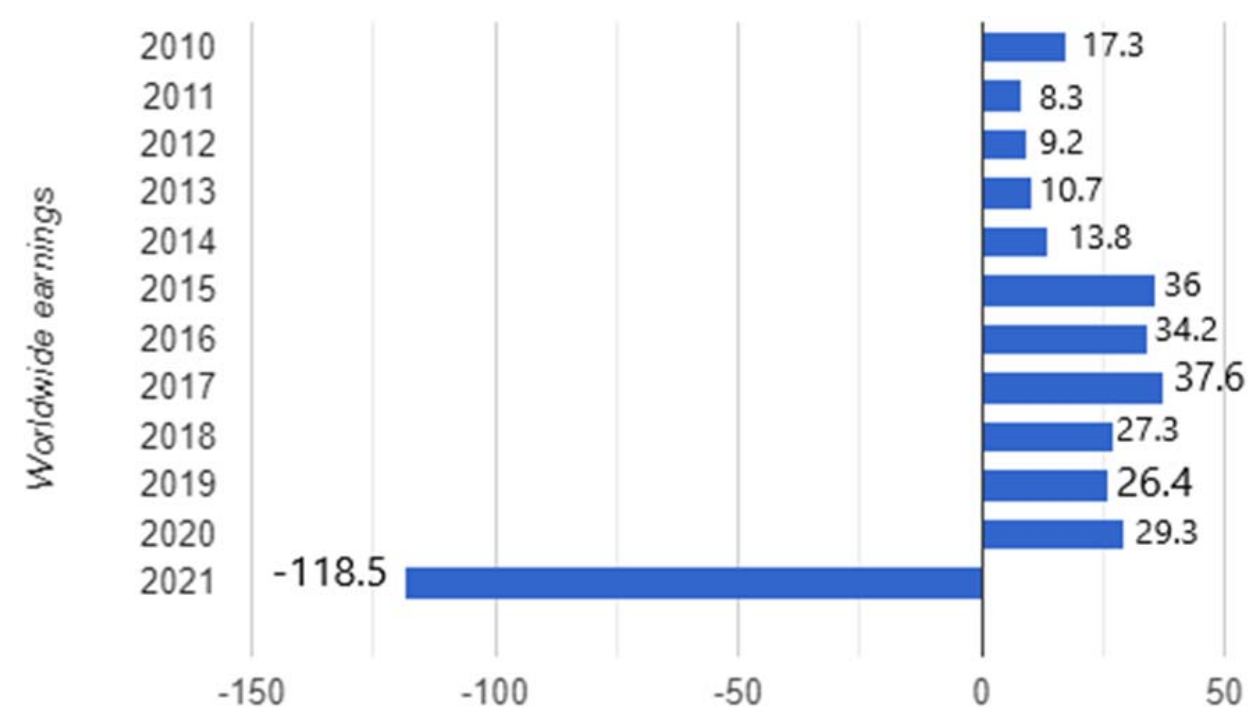

Profit in billion U.S. dollars

Figure 12. Profit due to digitalization in the aviation industry in period $2010-2021$ 
Figure 12. shows a worldwide profit due to digitalization in the aviation industry 2010-2021 as collected from ICAO.int, the Uniting Aviation United Nations Specialized Agency. Consumer expectations are changing all across the world as a result of digitalization. Because of its speed and size, businesses must rethink and reinvent their customer experiences in order to keep up, including new products, applications, and technologies to improve customer interactions [53].

\section{Conclusion}

In conclusion, a new wave of amazing and future-promising technology is something Aerospace and Defense companies are striving to achieve. These features are built to ease the process of manufacturing, customer service and financial growth and many companies recognize this. The cost of manufacturing significantly drops, customer service feedback is great and the financial growth is incomparable to that of older business models. But, for some companies, trying to navigate new technologies and business models doesn't go to plan. Converting to this new form of business, which lies on the platform of digitalization, is not an easy task. For a company to succeed in its attempt to digitalize, there are some unavoidable factors which need to be fulfilled. So, we believe, the issue is not in the new technology, but in humans running these operations and feeling comfortable with what they possess right now. Old business models are efficient, but not enough, and not for long, as virtually everything now relies on those principles listed earlier: manufacturing efficiency, customer service and financial growth.

This technological revolution, on its own, possesses a great opportunity for those ready to take a leap and risk what they have to conform to change, and companies which are ready to step out their comfort zone should be greatly rewarded in the future, as a technological future is inevitable.

\section{References}

[1] S. I. Tay, T. C. Lee, N. Z. A. Hamid, and A. N. A. Ahmad, "An overview of industry 4.0: Definition, components, and government initiatives,” J. Adv. Res. Dyn. Control Syst., vol. 10, no. 14, pp. 1379-1387, 2018.

[2] G. Reinhard, V. Jesper, and S. Stefan, "Industry 4.0: Building the digital enterprise," 2016 Glob. Ind. 4.0 Surv., pp. 1-39, 2016, [Online]. Available: www.pwc.com/industry40.

[3] L. Barbier, "Industrial 4.0 Adoption for US Aerospace and Defense Sector," vol. 53, no. 9, pp. 15-16, 2020.

[4] S. I. Tay, T. C. Lee, N. Z. A. Hamid, and A. N. A. Ahmad, "An overview of industry 4.0: Definition, components, and government initiatives," J. Adv. Res. Dyn. Control Syst., vol. 10, no. 14, pp. 1379-1387, 2018.

[5] A. Schirrmann, "Analysis of Control Strategies for A/C Production Ramp-Up," 2014.

[6] T. Margaria and A. Schieweck, "The Digital Thread in Industry 4.0," Lect. Notes Comput. Sci. (including Subser. Lect. Notes Artif. Intell. Lect. Notes Bioinformatics), vol. 11918 LNCS, pp. 3-24, 2019, doi: 10.1007/978-3-030-34968-4_1

[7] 'Understanding the 'Digital Thread' in Aerospace \& Defense INFOGRAPHIC

[8] "Digital Transformation in Aerospace \& Defense MYTH OR REALITY ? How Does Digital Transformation Create Value in A \& D ? Harsh Reality : Most A \& D Digital Transformations Fail Complete, Quality Data," p. 4, 2020.

[9] H. Ebbesen and C. Machholdt, "Digital Reality changes everything," 2019.

[10] L. Barbier, "Industrial 4.0 Adoption for US Aerospace and Defense Sector," vol. 53, no. 9, pp. 15-16, 2020.

[11] D. Literacy and M. Industry, “Digital Literacy Meets Industry 4.0,” Educ. Employab. (Volume 2), pp. 37 50, 2019, doi: 10.1163/9789004418707_004.

[12] T. Weber et al., "Defence trends 2020: Investing in a digital future," vol. Annual Glo, no. 23, p. 39, 2020, [Online]. Available:

www.pwc.com/defence-trends-2020. 
[13] A. General, "Digital Transformation in the Aviation Sector," no. April, 2017.

[14] M. During et al., "Harness Power of Big Data Through," pp. 1-3, 2021.

[15] G. Keifer and F. Effenberger, Title unavailable, Angew. Chemie Int. Ed., vol. 6, no. 11, pp. 951-952,

[16] "Study $\gg>$ Digitalization of the supply chain Successful Management of Aerospace Supply Chain Networks Challenges and Solutions Further Information.”, Stegkemper GmbH, 2016. Available: https://www.supplyon.com/img/Survey_Digitalization_Aerospace-Supply-Chain_2016_EN.pdf

[17] R. Fioravanti, S. Kraiselburd, and L. M. Laporte, "Monitoring and assesing the impact of Supply Chain 4.0 in Latin America," Inter-American Dev. Bank, p. 41, 2019.

[18] R. Waslo, T. Lewis, R. Hajj, and R. Carton, "Managing risk in an age of connected production," Deloitte Univ. Press, vol. 1, pp. 1-22, 2017, [Online]. Available:

https://www2.deloitte.com/us/en/insights/focus/industry-4-0/cybersecurity-managing-risk-in-age-ofconnected-production.html\%0Ahttps://dupress.deloitte.com/dup-us-en/focus/industry-4-0/cybersecuritymanaging-risk-in-age-of-connected-production.html\%0Ahttps.

[19] KPMG, "Defending the aerospace and defense sector," pp. 1-8, 2017.

[20] R. Lineburger, A. Hussain, T. Hanley, V. Rutgers, and B. Sniderman, "Aerospace \& Defence 4.0," Deloitte Insightsfile, p. 1, 2019.

[21] M. Littlefield, M. Davidson, G. Goodwin, "The Global State Of Manufacturing Operations Weaving the Digital Thread Across Industrial Value Chains", Apr 28, 2015.

[22] J. Hercko, E. Slamkova, and J. Hnat, "Industry 4.0 as a factor of productivity increase," Transcom 2015, no. March, pp. 1-5, 2015, [Online]. Available:

https://www.researchgate.net/publication/285597330_Industry_40_as_a_factor_of_productivity_increase /link/56f1a70108aee9c94cfd70c8/download.

[23] Airbus, 'European Union project 'ARUM' to provide flexibility for small-lot producers and production ramp-up of new, complex products" press release, November 5, 2012; AnyLogic, "Airbus Group: Analysis of management strategies for the aircraft production ramp-up" accessed April $4^{\text {th }}, 2021$.

[24] D. Ibarra, J. Ganzarain, and J. I. Igartua, "Business model innovation through Industry 4.0: A review," Procedia Manuf., vol. 22, no. May 2020, pp. 4-10, 2018, doi: 10.1016/j.promfg.2018.03.002.

[25] Dassault Systemes, "Dassault Systemes and BoostAerospace announce "AirDesign" collaboration platform", July 15, 2014

[26] G. Culot, F. Fattori, M. Podrecca, and M. Sartor, "Addressing Industry 4.0 Cybersecurity Challenges," IEEE Eng. Manag. Rev., vol. 47, no. 3, pp. 79-86, 2019, doi: 10.1109/EMR.2019.2927559.

[27] G. Reinhard, V. Jesper, and S. Stefan, "Industry 4.0: Building the digital enterprise," 2016 Glob. Ind. 4.0 Surv., pp. 1-39, 2016, [Online]. Available: www.pwc.com/industry40.

[28] P. Kumar, Y. Dasari, A. Jain, and A. Sinha, "Digital Nations - Smart Cities, Innovation \& Sustainability," no. October, pp. 276-288, 2017, doi: 10.1007/978-3-319-68557-1.

[29] D. Ibarra, J. Ganzarain, and J. I. Igartua, "Business model innovation through Industry 4.0: A review," Procedia Manuf., vol. 22, no. May 2020, pp. 4-10, 2018, doi: 10.1016/j.promfg.2018.03.002.

[30] K. K. Patel, S. M. Patel, and P. G. Scholar, "Internet of Things-IOT: Definition, Characteristics, Architecture, Enabling Technologies, Application \&amp; Future Challenges," Int. J. Eng. Sci. Comput., vol. 6 , no. 5, pp. 1-10, 2016, doi: 10.4010/2016.1482.

[31] M. Elkhodr, S. Shahrestani, and H. Cheung, "The Internet of Things : New Interoperability, Management and Security Challenges," Int. J. Netw. Secur. Its Appl., vol. 8, no. 2, pp. 85-102, 2016, doi: 10.5121/ijnsa.2016.8206.

[32] D. P. F. Möller, "Introduction to the Internet of Things," pp. 141-184, 2016, doi: 10.1007/978-3-31925178-3_4.

[33] Y. Fathy, P. Barnaghi, and R. Tafazolli, "Large-Scale indexing, discovery, and ranking for the internet of things (IoT)," ACM Comput. Surv., vol. 51, no. 2, pp. 1-67, 2018, doi: 10.1145/3154525. 
[34] V. Cerf, P. Ryan, M. Senges, and R. Whitt, "IoT safety and security as shared responsibility," Bus. Informatics, vol. 2016, no. 1, pp. 7-19, 2016, doi: 10.17323/1998-0663.2016.1.7.19.

[35] V. E. Badea, A. Zamfiroiu, R. Boncea, "Big Data in the Aerospace Industry," Inform. Econ., vol. 22, no. 1/2018, pp. 17-24, 2018, doi: 10.12948/issn14531305/22.1.2018.02.

[36] GSMA, "Understanding the Internet of Things (IoT)," Gsma Connect. Living, no. July, p. 15, 2014, [Online]. Available: http://www.gsma.com/connectedliving/wp-content/uploads/2014/08/cl_iot_wp_07_14.pdf.

[37] European Helicopter Safety Team, "Teaching and Testing in Flight Simulation Training Devices (FSTD)," 2015, [Online].

[38] Y. Riahi and S. Riahi, "Big Data and Big Data Analytics: concepts, types and technologies," Int. J. Res. Eng., vol. 5, no. 9, pp. 524-528, 2018, doi: 10.21276/ijre.2018.5.9.5.

[39] M. A. Frigo, E. C. C. da Silva, and G. F. Barbosa, "Augmented Reality in Aerospace Manufacturing: A Review,” J. Ind. Intell. Inf., no. January 2016, 2016, doi: 10.18178/jiii.4.2.125-130.

[40] J. Mariani, B. Sniderman, and C. Harr, "More real than reality Transforming work through augmented reality," Deloitte Rev., no. 21, Jul. 2017.

[41] N. Alberto Fonte Silva Lima, P. da Graça Tavares Álvares Serrão, and A. Martins Abrantes Leite, "Development of an Aircraft Health Monitoring Program for Predictive Maintenance Aerospace Engineering Examination Committee," no. December, p. 118, 2017, [Online].

[42] F. De Pace, F. Manuri, and A. Sanna, "Augmented Reality in Industry 4.0," Am. J. Comput. Sci. Inf. Technol., vol. 06, no. 01, pp. 1-7, 2018, doi: 10.21767/2349-3917.100017.

[43] H. Ebbesen and C. Machholdt, "Digital Reality changes everything," 2019.

[44] B. Karanjia, S. Veerapaneni, S. Gupta, S. Goswami, S. Sudhir, and Delloite, "Virtual, augmented, and mixed reality for defence and the public sector," no. July, 2019.

[45] J. Fitzgerald and E. Quasney, "Using autonomous robots to drive supply chain innovation," Deloitte, p. 12, 2017, [Online].

[46] H. Ebbesen and C. Machholdt, "Digital Reality changes everything," 2019.

[47] C. Computing, "Disruptive Information Technologies Disruptive Information Technologies," no. September 2010.

[48] H. Ebbesen and C. Machholdt, "Digital Reality changes everything," 2019.

[49] J. Coykendall, M. Cotteleer, L. Holdowsky, and M. Mahto, "3D opportunity in Aerospace and Defense," Deloitte Univ. Press, pp. 1-28, 2014.

[50] T. Aerospace, "What future for Intelligent Automation in Aerospace and Defence ?," no. April, 2018.

[51] B. Environment, "The Internet of Things in Commercial Buildings," 2014.

[52] N. Rachel Suresh and S. V. Mathew, "Security concerns for cloud computing in aircraft data networks," 2011 International Conference for Internet Technology and Secured Transactions, 2011, pp. 132-136.

[53] A. Chavali, “Aerospace \& Defense Companies Must Make the Right Connections for New Growth,” p. 6, 2017, [Online]. Available: https://www.accenture.com/t20171211T045641Z_w__us-en/_acnmedia/PDF-67/Accenture-DigitalThread-Aerospace-And-Defense.pdf.

[54] GSMA, "Understanding the Internet of Things (IoT)," Gsma Connect. Living, no. July, p. 15, 2014, [Online]. Available:

http://www.gsma.com/connectedliving/wp-content/uploads/2014/08/cl_iot_wp_07_14.pdf.

[55] D. P. F. Möller, "Introduction to the Internet of Things," pp. 141-184, 2016, doi: 10.1007/978-3-31925178-3_4.

[56] D. McFarlane, "Industrial Internet of Things: Applying IoT in the Industrial Context," Connect. Everything, pp. 3-14, 2018, [Online]. Available: www.ifm.eng.cam.ac.uk/insights/automation/iiot-report/. 
[57] A. General, "Digital Transformation in the Aviation Sector," no. April, 2017.

[58] R. Lineburger, A. Hussain, T. Hanley, V. Rutgers, and B. Sniderman, "Aerospace \& Defence 4.0," Deloitte Insightsfile, p. 1, 2019, [Online]. Available:

https://www2.deloitte.com/us/en/insights/focus/industry-4-0/aerospace-defense-companies-digitaltransformation.html.

[59] "Global IoT market in Aerospace \& Defense (2019-2026)." Available:

https://www.maximizemarketresearch.com/market-report/global-iot-in-aerospace-defense/10721/ (accessed Aug. 01, 2021).

[60] B. Durakovic and E. Trgo, "Perspectives and the role of Bosnian defense industry in national innovation system," Defense and. Security Studies, vol. 1, pp. 26-33, Apr. 2021, doi: 10.37868/dss.v1.id145. 